mediastudies.press • Social Media \& the Self: An Open Reader

\title{
Layers of Identity: How to Be "Real" When Everyone Is Watching
}

Crystal Abidin

Published on: Apr 16, 2018

DOI: $10.32376 / 3 f 8575 c b . a 3133 b 0 f$

License: Copyright $@$ All rights reserved. (COPYRIGHT) 
WITH THE RISE of online influencers and their conscientiously maintained feeds full of images of luxury, the accessibility once promised by their predecessors, microcelebrities, has been eroded. For their followers, microcelebrities were a more visible version of the ordinary person, albeit being closer to fulfilling collective aspirations of wealth and health. They were taken as role models, offering life-hacks and pro tips for attaining life goals, with their personal lifestyles serving as proof. This mainly played out through their endorsing particular products and services and sometimes amplifying some trends over others through their opinion editorials. But unlike the lives of celebrities in the mainstream entertainment industry who also dabble in endorsements, the lives of microcelebrities felt easier to emulate and to possibly attain. They had a knack for discussing prosperity and pimples, charms and chores in the same breath.

Influencer culture began in the late 1990s and mid-2000s; in Southeast Asia it was on blog platforms such as OpenDiary, LiveJournal, Xanga, and Blogspot. In China it was on discussion boards. In the U.S., it was through home webcamming. Before the internet, marketing through the endorsements of "ordinary people" was a matter of scouts recruiting popular high school and university students to model specific wares on campus and promoting student parties and clubs.

In its early days, lifestyle blogging's allure was premised on the diary-like reportage of people's everyday lives, in the rhetoric of confessional documentaries. The regularity and frequency of their updates mirrored the daily rhythms of a teenager's social life and attracted followers: Their blogs became a means for other girls to learn how to be social through consumption, within their modest spending power. Today, these early commercial lifestyle bloggers are among the most seasoned veterans in influencer culture, innovating with new disclosure strategies to sustain followers over their decade-long careers.

By the early 2010s, microcelebrity culture had flourished into a full-fledged influencer industry, where young people on Instagram especially armed themselves with luxury items to convey success and in-group status while attempting to appear effortless and intimate to followers. But with their rise, influencers' practice and persona have become both overfamiliar and more unattainable-requiring more money, connections, inside knowledge. And given the hypersaturation of the influencer industry today, where even entry-level aspirants must prime themselves to debut as extremely professional and polished, the pretty, pristine, and picturesque have started to become 
boring: Yet another flawless selfie, branded fashion OOTD (outfit of the day), or holiday vlog in an exotic destination may not have the impact it once had.

To differentiate themselves from the mass market, some influencers, whether through reactionary instinct or intentional strategy, have begun to break away from the "picture perfect" mold of Instagram and return to the early lifestyle-blogging claims of a more "authentic" version of themselves, the influencer industry, and everyday life. Amid the noise of picture-perfect Barbies, they believe that what followers now want is to see "real life," unfiltered, unmediated, and uncurated. And to restore this illusion of accessibility, influencers use the notion of authenticity as a springboard to rebrand themselves as "more real" than the others. But what is "real life" anyway?

In thinking about digital identity, we need go beyond dichotomies that posit the online is "fake" and the offline more "authentic," given that all self-presentation in digital and physical spaces is curated and controlled. Authenticity has become understood less as static and more as a performative ecology and parasocial strategy with its own genre and self-presentation elements. In other words, for influencers to convince an audience that they are being authentic, it is not enough for them to merely show themselves without "artifice": barefaced, with a bedhead, and in pajamas. Instead, they must actively juxtapose this stripped-down version of themselves against the median and normative self-presentations of glamour, to continually create and assign value to new markers-faults and flaws, failures and fiascos-to affirm the veracity of their truth-ness.

At the heart of contorting one's digital front to appear more "real" is the desire to feel more "relatable." Among the influencers I have been studying since the late 2000s, the idea of relatability frequently appears in such comments as "I need to make my posts relatable," or "She managed to make that event so relatable," or "I feel I am more relatable" than a rival influencer. In their usage, relatability is a vague description that assigns value to styles of writing, the management of situations, and the performance of personae without prescribing a particular formula. When pressed, some influencers admit that the term's vagueness means it can be selectively applied to preserve an idea of meritocracy. Others assert that it can be honed through gut feeling ("it just feels right") and trial and error ("the more you practice the more you will know").

Unarticulated and inarticulatable, relatability is a form of what I have called "tacit labor," the embodied and intentionally unseen work required to make a practice seem natural or effortless. Relatability is a vernacular term whose vagueness masks its interrelated subqualities: accessibility (how easy it is to approach an influencer in 
digital and physical spaces), believability (how convincing an influencer's depicted lifestyle and sentiments are), authenticity (how genuine an influencer's actual lifestyle and sentiments are), emulatability (how easy followers can model themselves after an influencer's lifestyle), and intimacy (how familiar and close followers feel to an influencer).

But how is relatability put to work? One strategy is what I have labeled calibrated amateurism, in which influencers deliberately try to portray the raw aesthetic of a novice. Calibrated amateurism is a modern adaptation of Erving Goffman's theory of scheduling in The Performance of Self in Everyday Life and Dean MacCannell's theory of "staged authenticity." Goffman argues that on stage as in everyday life, performers may engage in "scheduling" to separate different audiences, so that different aspects of the performer's persona can be presented as required. This also permits performers to obscure the "routine character" of their act and stress its apparent spontaneity. This sometimes involves the deliberate effort to manufacture a "back region"-a seemingly off-stage persona that is nonetheless part of a deliberate performance.

MacCannell studied similar back regions in tourist settings in and argues that tourists, in their pursuit of authenticity, are complicit in their manufacture. He writes that "just having a back region generates the belief that there is something more than meets the eye; even where no secrets are actually kept, back regions are still the places where it is popularly believed the secrets are." He argues that "their mere existence, and the possibility of their violation, functions to sustain the common-sense polarity of social life into what is taken to be intimate and 'real' and what is thought to be 'show.'”

Combining these two classical theories, we can see how influencers today also partake in deliberately curated and intentionally public forms of backchanneling, through Finstagrams ("fake" accounts) and multiple Instagram accounts, which encourage followers and viewers to hop, watch, and match across Instagram and other social media accounts. Such corroborative cross-platforming work gives to followers who are curious, loyal, and willing to commit to the laborious detective work the assurance that they have privileged access to an influencers' multi-faceted and multi-layered persona, across a long spectrum of disclosures. The implication of these practices is that we all have backstages and hidden secrets on display on parallel platforms, if only an audience knows where and how to look for these Easter eggs.

Savvy influencers can pander to their followers' search for those breaks in frame, producing content that specifically baits them. These posts may focus on the struggles, hardship, and dirty laundry of the industry, including how hate comments affect them, 
the precarity of their volatile income, and the pressures of being constantly scrutinized. These constitute a genre known colloquially as "BTS posts" for "behind the scenes." While BTS posts originally began as unintended slippages or occasional but genuine revelations of the backstage, soon influencers started secondary social media accounts they claimed were "uncurated," "undirected," "not commercial," or "less pretty" to upload content that may not have been congruent with their public branding. Such shadow accounts were not as actively touted as influencers' primary cash-cow accounts; influencers claimed they allowed them to experience Instagram as ordinary users rather than internet celebrities.

In interviews, influencers explained to me that shadow feeds were a "highlight reel" of snaps that did not make their primary feeds, that they were "truer representations" of their everyday lives, and that the backchannel let followers "get to know influencers better." BTS posts and shadow accounts initially enabled influencers to present the image of a second, more authentic self to followers, albeit still negotiated on public feeds on Instagram. Still, some influencers began to adopt such hashtags as \# natural, \#noedit, \#nofilter, \#nomakeup, and \#nophotoshop in a bid to stand out from their colleagues and blend in with the everyday social media user.

Everyday users also partook in this movement, generating apparently $a u$ naturel images of themselves asleep, as in \#baecaughtmeslippin, or freshly awake in bare face, as in \#iwokeuplikethis. However, these memes soon evolved into viral parody as more users invested more effort in staging the natural rather than being natural.

In her book Authentic ${ }^{T M}$, communications scholar Sarah Banet-Weiser reminds us that "digitally aided disclosure such as building a self-brand on MySpace or Facebook, relies on traditional discourses of the 'authentic' self as one that is transparent, without artifice, open to others ... authenticity not only is viewed as residing inside the self but also is demonstrated by allowing the outside world access to one's inner self." In their strategy to disclose more of their apparently "authentic" selves, influencers often attempt to emphasize a false divide between their digital representations on social media and their actual lives as lived offline, by asserting that online and offline are distinct spheres-what social media theorist Nathan Jurgenson has termed "digital dualism." By continuously alluding to their more secret, more genuine, more real "real lives," influencers aim to create a backstage region in which they can invite followers to assess how genuine they really are. I term this practice "porous authenticity": An audience is enticed into trying to evaluate and validate how genuine a persona is by 
following the feedback loop across the front stage of social media and the backstage of "real life," through inconspicuous and scattered holes or gateways that were intentionally left as trails for the curious.

The authenticity of influencers' self-presentation in digital spaces is measured against their "off-duty" self-expression, usually accessed by followers in search of "leaks" and "bleeds" from influencers' offline lives. Such corroborative cross-referencing work is so thorough that it has become colloquially known as "CSI-ing," after the crime show.

Porous authenticity was in play in the scandal surrounding Essena O'Neill, an 18-yearold Australian influencer. She made a viral video in which she announced while crying on camera that she was quitting the industry due to the "dark side" of social media and the pressure to keep up a façade for her brand. O’Neill re-captioned her Instagram advertorials that were previously paid for by clients with scathing comments on how she starved herself for a bikini body, how much each post earned her, or how she was struggling with depression despite her cheery selfies. She also changed the names of her Instagram account and website to Let's Be Game Changers and called on influencers and followers to denounce how "fake" social media was, proclaimed that "social media is not real life," and that users should "live authentic lives." She also repeatedly disavowed influencer commerce, claiming that she would never again engage in social media posts that were monetized. Yet, another tab on her new site featured "Cool Products," in which the influencer was still marketing products to followers. Then, just as quickly as she had rebranded her digital estates, O’Neill set her Instagram to private and deleted her website.

O'Neill's attempted rebranding echoes a strategy that Banet-Weiser calls "commodity activism." In this case, O’Neill tried to rebrand herself as a better breed of influencer (non-commercial engagements instead of advertorials) with a higher calling (purposeful living instead of a public social media life) for social activism (digital detox, wellness) that nonetheless can be attained through consumption (health foods, veganism, yoga). Evidently, being able to skillfully build a continuum of self-disclosure along which one can manipulate and maneuver between layers of authenticity and truth-ness can be a highly viable endeavor. And it is the most seasoned of influencers who are able to master this dance well enough to claim longevity in the industry: I am me, I have always been me, and I will always be me-and you can be assured of this, so long as you dive deep enough to collect all these versions of me.

The rise of calibrated amateurism and porous authenticity tells us that followers have become more savvy in their consumption of influencer content-and maybe more 
bored with it. Where it used to be premised on aspiration and vicarious living, it now pursues verification of the staged layers of truths and corroborating details among influencers' identity trails. This is how influencers teach us how to do real life when everyone is watching: They play with layers of visibility to conceal the slick and accentuate the sin, conceal the commerce and accentuate the community, conceal the artifice and accentuate the affect. And when they approach the next threshold of authenticity, influencers design new yardsticks of self-disclosure to persuade followers that they are just like them.

Dr. Crystal Abidin is an anthropologist and ethnographer who researches internet culture and young people's relationships with social media, technology, and devices. She is Postdoctoral Fellow with the Media Management and Transformation Centre at Jönköping University and Adjunct Research Fellow with the Centre for Culture and Technology at Curtin University. Reach her at wishcrys.com.

\section{REPRINT}

"Layers of Identity: How to Be 'Real' When Everyone Is Watching" (Crystal Abidin, Real Life, April 16, 2018)

REPRINTED WITH PERMISSION OF REAL LIFE, WHICH RESERVES ALL RIGHTS 